\title{
A sutureless valve with sutures.
}

\author{
Fernando Moraes $^{1}$ and Leonardo Mulinari ${ }^{2}$ \\ ${ }^{1}$ heart institute of pernambuco \\ ${ }^{2}$ University of Miami Miller School of Medicine
}

February 21, 2022

\begin{abstract}
The use of sutureless valves in infective endocarditis has been previously reported. Singh et al have reported a single-center
\end{abstract} successful surgical treated pulmonary endocarditis in 2 cases with a sutureless bioprosthesis.

A sutureless valve with sutures.

The use of sutureless valves in infective endocarditis has been previously reported. 11Weymann A, Konertz J, Laule M, et al. Are Sutureless Aortic Valves Suitable for Severe High-Risk Patients Suffering from Active Infective Aortic Valve Endocarditis? Med Sci Monit. 2017;23:2782-2787. 22Piperata A, Kalscheuer G, Metras A, Pernot M, Albadi W, Taymoor S, Peltan J, Oses P, Barandon L, Bottio T, Gerosa G, Labrousse L. Rapid-deployment aortic valve replacement in high-risk patients with severe endocarditis. J Cardiovasc Surg (Torino). 2020 Dec;61(6):769-775. doi: 10.23736/S0021-9509.20.11349-1. Epub 2020 Jun 19. PMID: 32558526. 33Fischlein T, Meuris B, Hakim-Meibodi K, et al. The sutureless aortic valve at 1 year: A large multicenter cohort study. J Thorac Cardiovasc Surg 2016;151:1617-26.e4

Singh et al 44Singh N, Peek K, Nand P. Novel use of the Perceval sutureless bioprosthesis for pulmonary valve replacement in high-risk endocarditis patients: a case series. J Cardiac Surgery have reported a single-center successful surgical treatment of 2 cases using a sutureless bioprosthesis in an infected pulmonary native valve. The implantation of these types of valves in active endocarditis may still be considered a relative contraindication. In these operations, the authors used a similar technique proposed for these implantable devices on the aortic position. However, some modifications were applied from the ones recommended by the manufacturer. Perceval valves were designed for aortic valve replacement in aortic valve stenosis. The traditional incision is a high transverse one, to avoid catching the stent when closing the vessel, in this case, the pulmonary artery. The authors used a longitudinal incision in the pulmonary artery. The use of this incision may have facilitated the visualization and resection of the vegetation, cusps, and implantation of the valve. Another point to discuss is the size of the device. The selected valves were XL. To properly fit those valves the reduction of annulus size was necessary. The authors also describe tieing the 3 guiding stitches so we can not consider it a sutureless valve anymore. Probably this modification was applied because the surgeon was not so confident to leave it sutureless. as recommended by the manufacturer. Was the beating heart technique used in these cases the reason for that? Both patients had a good recovery and the echocardiograms showed the valves functioning properly.

Despite 2 very challenging cases, the authors offered an excellent alternative technique with one of the best hemodynamically performing valves available today. The performance of the Perceval valve is well established in the aortic position. On the pulmonary position, we will need to wait for the follow-up to observe the performance of those valves.

Another interesting aspect is that in case of valve degeneration the use of a transcatheter valve will be an easy alternative to replace it due to the easy visualization of the valve stent. There is no doubt that these 
cases are innovative and bring a promising alternative to the group of patients with pulmonary valve disease, not only infective valves but also congenital pulmonary valve disease. 